\title{
Intestinal permeability in patients with Crohn's disease and their first degree relatives
}

\author{
K Teahon, P Smethurst, A J Levi, I S Menzies, I Bjarnason
}

\begin{abstract}
It has been reported that intestinal permeability to polyethylene glycol 400 is increased in patients with Crohn's disease and their apparently unaffected first degree relatives. Because of the implications that these findings have for the aetiology of Crohn's disease these studies were repeated. Patients with Crohn's disease $(n=28)$ and 32 first degree relatives from 11 families underwent a polyethylene glycol 400 (PEG400) intestinal permeability test and a hyperosmotic (1500 mosmol/1) absorption/permeability test using 3-0-methylD-glucose, D-xylose, L-rhamnose, lactulose, and ${ }^{51}$ chromium labelled ethylenediaminetetraacetate. The five hour urine excretion of polyethylene glycol $\mathbf{4 0 0}$ did not differ significantly between controls $(n=25)$ and first degree relatives, 25.5 (3.3)\% $v \quad 24.6 \%$ (4)\% (mean (SD)) $\mathbf{p}>\mathbf{0} \cdot \mathbf{1}$, respectively. Patients with small bowel involvement excreted significantly less $(\mathrm{p}<0.01)$ polyethylene glycol $400(16.3$ (4.6)\% than controls while those with Crohn's colitis did not $(26.4(3.9) \% \quad p>0.1)$. The permeation of the monosaccharides in patients with Crohn's disease and their first degree relatives did not differ from normal subjects. The permeation of lactulose and ${ }^{51}$ chromium ethylenediaminetetraacetate was not significantly altered in first degree relatives but was significantly increased in the patients, as was the lactulose/L-rhamnose urine excretion ratio which is a specific measure of small intestinal permeability. These studies show normal absorption and permeability in first degree relatives of patients with Crohn's disease. A genetically determined abnormality of intestinal permeability is not likely to be an important aetiological factor in Crohn's disease.
\end{abstract}

Section of

Gastroenterology, MRC Clinical Research Centre and Division of Gastroenterology, Northwick Park Hospital, Harrow, Middlesex

Department of Chemical Pathology and Metabolic Disorders, UMDS Guy's and St Thomas' Hospital Medical School, London K Teahon

P Smethurst

A J Levi

I S Menzies

I Bjarnason

Correspondence to: Dr I Bjarnason, Division Clinical Biochemistry, Kings College Hospital, Bessemer Road, London SE5.

Accepted for publication 2 July 1991 less well established and a propositus has about $10 \%$ chance of a lst degree relative having or developing either Crohn's disease or ulcerative colitis. ${ }^{67}$

The recent findings of increased intestinal permeability to polyethylene glycols [PEG400] (mean Mol wt 400) in patients with Crohn's disease and $66 \%$ of their apparently unaffected relatives is particularly important. ${ }^{8}$ It implies an inheritable genetic defect with direct relevance to the pathogenesis of the disease. Such a defect would lead to disease only if associated with a separate genetically determined or acquired derangement of immune responsiveness. . $^{9-11}$

In view of the important implications of these findings we sought to confirm the results by studying patients with Crohn's disease and their first degree relatives. Two test solutions were used, one containing PEG400 and another containing 3-0-methyl D-glucose, D-xylose, L-rhamnose, lactulose and ${ }^{51}$ chromium labelled ethylenediaminetetraacetate $\left({ }^{51} \mathrm{CrEDTA}\right)$ with a hyperosmotic stress to assess the integrity of the various permeation pathways used by these probes.

\section{Methods}

SUBJECTS

Twenty five healthy causcasian volunteers acted as controls. Twenty eight patients with Crohn's disease were studied. Table I shows the clinical details. Twelve patients with Crohn's disease (11 families) had two or more first degree relatives available and willing to take part in these studies. Thirty two apparently healthy first degree relatives were studied (representing $85 \%$ of those potentially available). Relatives under 18 were excluded and also subjects on non-steroidal antiinflammatory drugs.

\section{PROCEDURES}

Each subject was tested twice within a week, first with PEG400 and then with a combined absorption permeability test. All fasted from midnight until 10 am at whch time normal food and fluids were allowed. At 8 am the test solution was ingested. Complete urine collections were made for five hours ( 8 am to $1 \mathrm{pm}$ ) into a container containing $1 \mathrm{ml}(10 \% \mathrm{w} / \mathrm{v})$ of sodium ethyl mercurithiosalicylate (Thiomersal) as preservative for the sugar markers.

Test solution A contained: PEG400: $(5 \mathrm{~g})$ (BDH chemicals Ltd, Poole Dorset UK) in 100 $\mathrm{ml}$ water $(125 \mathrm{mosmol} / \mathrm{l})$.

Test solution B contained; 3-0-methyl-Dglucose: $(0.2 \mathrm{~g})$ (Sigma Chemical Co, Poole, Dorset UK) To assess active carrier mediated transport ${ }^{12}{ }^{13}$; D-xylose: $(0.5 \mathrm{~g})$ (Sigma Chemical Co) To assess passive carrier mediated transport ${ }^{12}{ }^{13}$; L-rhamnose: ( $\left.1 \mathrm{~g}\right)$, To assess small pore permeation. ${ }^{12} 13$

Lactulose: (5 g), (lactulose syrup, Duphar Laboratories Ltd, West End Southampton, UK): 
TABLE I Clinical details of patients with Crohn's disease

\begin{tabular}{|c|c|c|c|c|c|c|c|}
\hline & Sex & Age & $\begin{array}{l}\text { Site of } \\
\text { disease }\end{array}$ & $\begin{array}{l}\text { Length of } \\
\text { history }(y r)\end{array}$ & Surgery & $\begin{array}{l}\text { Previous } \\
\text { treatment }\end{array}$ & $\begin{array}{l}\text { Treatment of } \\
\text { time of study }\end{array}$ \\
\hline 1 & M & 28 & Small bowel & 9 & _- & $\mathrm{P}, \mathrm{ED}, \mathrm{SP}$ & $\mathrm{Nil}$ * \\
\hline 2 & $M$ & 45 & Small bowel & 30 & SBR & Nil & Nil \\
\hline 3 & $\mathrm{~F}$ & 33 & Small bowel & 8 & - & Nil & Nil * \\
\hline 4 & $M$ & 28 & Ileal & New & - & Nil & ED \\
\hline 5 & $\mathrm{~F}$ & 28 & Ileal & New & - & Nil & Nil \\
\hline 6 & M & 55 & Ileal & 20 & - & SP & Nil \\
\hline 7 & $\mathrm{~F}$ & 24 & Ileal & New & - & Nil & Nil \\
\hline 8 & M & 18 & Ileal & 1 & - & $\mathrm{P}$ & $\mathrm{ED}$ * \\
\hline 9 & $\mathrm{M}$ & 60 & Ileal & 30 & ITA & Nil & Nil \\
\hline 10 & $M$ & 58 & Ileal & 20 & ITA & $\mathrm{P}, \mathrm{SP}$ & Nil \\
\hline 11 & $\mathrm{~F}$ & 54 & Ileal & 30 & TC & $\mathrm{P}, \mathrm{ED}$ & Nil \\
\hline 12 & $\mathrm{~F}$ & 40 & Ileal & 11 & TC & ED, SP & $\mathrm{Nil}$ * \\
\hline 13 & $M$ & 62 & Ileocolonic & 2 & - & Nil & Nil \\
\hline 14 & $\mathrm{~F}$ & 30 & Ileocolonic & 6 & Sub TC & $\mathrm{P}, \mathrm{ED}, \mathrm{SP}$ & $\mathrm{Nil}$ * \\
\hline 15 & $\mathrm{~F}$ & 27 & Ileocolonic & 2 & - & $\mathrm{P}, \mathrm{ED}, \mathrm{SP}$ & Nil * \\
\hline 16 & $\mathrm{~F}$ & 21 & Colonic & New & - & Nil & Nil * \\
\hline 17 & M & 21 & Colonic & 1 & - & $\mathrm{P}, \mathrm{SP}$ & $\mathbf{P}$ \\
\hline 18 & $\mathrm{M}$ & 33 & Colonic & 14 & - & SP & - \\
\hline 19 & $\mathrm{M}$ & 28 & Colonic & 3 & _- & $\mathrm{P}, \mathrm{ED}, \mathrm{SP}$ & Nil * \\
\hline 20 & $\mathrm{~F}$ & 22 & Colonic & 3 & _- & ED & Nil \\
\hline 21 & $\mathrm{~F}$ & 38 & Colonic & New & - & Nil & Nil \\
\hline 22 & $M$ & 44 & Colonic & 16 & - & SP & Nil \\
\hline 23 & $\mathrm{M}$ & 28 & Colonic & New & _- & Nil & Nil \\
\hline 24 & $\mathrm{~F}$ & 27 & $t$ & 13 & ITA & $\mathrm{P}$ & Nil * \\
\hline 25 & $\mathrm{~F}$ & 28 & $t$ & 7 & ITA & $\mathrm{P}, \mathrm{ED}$ & Nil \\
\hline 26 & $\mathrm{~F}$ & 26 & $t$ & 8 & ITA & $\mathrm{P}, \mathrm{ED}$ & $\mathrm{Nil}$ * \\
\hline 27 & M & 35 & $t$ & 5 & $\mathrm{TC}$ & $\mathrm{P}, \mathrm{ED}, \mathrm{SP}$ & Nil * \\
\hline 28 & $\mathrm{~F}$ & 55 & $t$ & 20 & TC & Nil & Nil * \\
\hline
\end{tabular}

$\mathrm{ED}=$ elemental diet, $\mathrm{ITA}=$ ileotransverse anastomosis, $\mathrm{P}=$ prednisolone, $\mathrm{SP}=$ sulphapyridine, $\mathrm{SBR}=$ partial small bowel resection, $\mathrm{TC}=$ total colectomy ${ }^{\star}{ }^{\star}=$ family studied, $\dagger=$ no evidence of recurrent disease.
To assess large pore permeation ${ }^{12}{ }^{13} ;{ }^{51} \mathrm{CrEDTA}$ : $(100 \mu \mathrm{Ci})$; Amersham International, Amersham, Buckinghamshire, UK): To assess large pore permeation, ${ }^{12}{ }^{13}$ with glycerol: $(6.0 \mathrm{ml})$ as an osmotic filler to make a final osmolality of $1500 \mathrm{mosmol} / \mathrm{l}$.

\section{MARKER ANALYSIS}

\section{Analysis of PEG400}

The total five hour urine collection is diluted to $500 \mathrm{ml}$ with water. Five millilitres of this diluted urine is mixed with $50 \mu \mathrm{l} \%$ (v/v) tetraethylene diethylglycol (Sigma Chemical Co,) as internal standard. The sample is then rotary mixed with $1 \mathrm{~g}$ amberlite $\mathrm{MBI}$ resin (BDH Chemicals Ltd) for 10 minutes. Another $1 \mathrm{~g}$ resin is added and mixed for a further 10 minutes. The sample is then centrifuged at $2000 \mathrm{~g}$ for 10 minutes and 20 $\mu l$ of the supernatant is analysed by high pressure liquid chromatography (HPLC) for the separate components of polyethylene glycol.

The high pressure liquid chromatography system used consists of a $5 \mu \mathrm{m}$ Hypersil ODS column $(25 \mathrm{~cm} \times 5 \mathrm{~mm}$ ) (Runcorn, Cheshire, UK) through which $30 \%$ methanol in $0.1 \mathrm{M}$ amonium acetate is pumped at a rate of $1 \mathrm{ml} / \mathrm{min}$. The eluent is then passed through a refractive index detector (R1-4, Varian $0.5 \times 10^{-5}$ RIU/FS

TABLE II Five hour urine excretion of sugars and ${ }^{5 /} \mathrm{CrEDTA}$

\begin{tabular}{lllllll}
\hline & $\begin{array}{l}\text { 3-0-methyl-D } \\
\text { glucose }\end{array}$ & D-xylose & L-rhamnose & Lactulose & "CrEDTA & $\begin{array}{l}\text { Lactulosel } \\
\text { L-rhamnose }\end{array}$ \\
\hline $\begin{array}{l}\text { Control } \\
\text { lst degree } \\
\text { relatives }\end{array}$ & $39.0(8.3) \%$ & $24 \cdot 7(5.8) \%$ & $9 \cdot 4(2 \cdot 6) \%$ & $0.37(0.21) \%$ & $0.57(0.25) \%$ & $0.039(0.020)$ \\
$\begin{array}{c}\text { Crohn's } \\
\text { disease }\end{array}$ & $33.3(11.4) \%$ & $24.4(6.4) \%$ & $10.7(4.3) \%$ & $0.53(0.31) \%$ & $0.74(0.31) \%$ & $0.050(0.017)$ \\
\hline
\end{tabular}

Value represents mean (SD) urine excretion (\% dose) in five hours *differs significantly from control $(\mathrm{p}<0 \cdot 05)$.
Varian instrument group, Walnut Creek, Ca, USA) attached to a pen chart recorder (Philips PM 8251 recorder, Cambridge, UK).

Using this method nine ethylene glycol polymers are derived. Only the five species (PEG polymers $3-7$, mol wt 282-458) that give the clearest definition are calculated. The method is sensitive with a minimal level of detection of 5 mg PEG400/1 urine.

\section{ANALYSIS OF SUGAR MARKERS}

Urinary lactulose was estimated as by Noon $e t$ $a l .{ }^{14}$ Urine was desalted by shaking with Duolite MB5113 mixed anion-cation exchange resin (BDH Chemicals Ltd) in the $\mathrm{H}^{+}$, acetate form and run in parallel with appropriate standard applications, on $46 \mathrm{~cm} \times 56 \mathrm{~cm}$ sheets of Whatman no 3 chrome paper (Whatman Laboratory Products Ltd, Springfield Mill, Maidstone, Kent, UK) with butan -1-ol/ethylacetate/ pyridine/water (30:30:30:15 by vol: 20 hour descending). After 4-aminobenzoic/orthophosphoric acid colour reaction, the separated zones were measured with a recording and intergrating densitometer (chromosan 200, Joyce-Laebl and Co Ltd, Team Valley, Gatehead, Durham, UK). Lactulose concentrations were calculated by comparison of test with standard peak areas assuming a linear relationship below $20 \mu \mathrm{g} /$ zone.

A modified thin layer chromotographic technique was used for estimating urine 3-0-methyl-D-glucose, D-xylose and Lrhamnose. ${ }^{1516}$ This involves measurement of peak heights by scanning densitometry incorporating an arabinose internal standard to overcome errors of application. Sugar separation was achieved by multiple development on half plates $(10 \mathrm{~cm} \times 20 \mathrm{~cm})$ of plastic backed silica gel 60 (Merck, Darmstadt, Germany) using three consecutive ascending runs $(8.5 \mathrm{~cm}$ each) with ethylacetate/pyridine/acetic acid/water (75:15:10:10:, by vol). The layers were dried for at least 30 minutes between each run, and for four hours to remove pyridine before performing a 4-aminobenzoic acid/orthophosphoric acid colour reaction at $120-130^{\circ} \mathrm{C}$ for 10 minutes. After localisation chromatograms were kept refrigerated in polyethylene envelopes and exposure was minimised during scanning. Peak heights were measured and corrected to a constant internal standard value. Test concentrations were then divided by interpolation from a standard L-rhamnose D-xylose, 3-0-methyl-Dglucose concentration curves from the same chromatograms.

The chromatographic procedures have a minimum level of detection of below $0.1 \mathrm{mmol} / \mathrm{l}$ for the sugars and recovery above $90 \%$. The coefficient of variation without replication lies between 3 and $8 \%$ over the test range of sugar concentration.

\section{ANAL YSIS OF ${ }^{\text {II }}$ CrEDTA}

Five millilitre aliquots of measured urine volumes were counted in a Wallac LKB 1280 gamma counter for five minutes with $5 \mathrm{ml}$ of a 1:500 dilution of the appropriate stock test 
solution. Sensitivity was $0.03 \%$ of the administered dose per litre of urine, and the precision between 1.0 and $5.0 \%$ depending on the level of activity.

\section{STATISTICAL ANALYSIS}

Wilcoxon's rank-sum test was used to assess significances between groups.

\section{Results}

Figure 1 shows the five hour urine excretion of PEG400. The mean (SD) excretion from controls $25 \cdot 5(3 \cdot 3 \%)$ did not differ significantly ( $\mathrm{p}>0 \cdot 1)$ from patients with Crohn's disease, 21.6 $(7 \cdot 2) \%$ or their first degree relatives $24 \cdot 6 \%$. Figure 2 shows the PEG400 results from the patients with Crohn's disease when grouped according to disease location. Patients with small intestinal involvement have significantly reduced permeation of PEG400 (16.3 (4.6))\% while patients with Crohn's colitis only, are mostly within the normal range.

Table II shows the five hour urine excretion of 3-0-methyl-D-glucose, D-xylose, L-rhamnose, lactulose and ${ }^{\text {SI }} \mathrm{CrEDTA}$. The urine excretion of monosaccharides in patients with Crohns disease and their first degree relatives did not differ significantly $(p>0.1)$ from controls. The first degree relatives had excretion values of lactulose and ${ }^{51} \mathrm{CrEDTA}$ which did not differ significantly from controls but patients with Crohn's disease had significantly increased permeation of both markers. The lactulose/L-rhamnose urine excretion ratio, a specific measure of intestinal inflammation largely unaffected by other determinants of single marker permeation rates, ${ }^{12}$ is

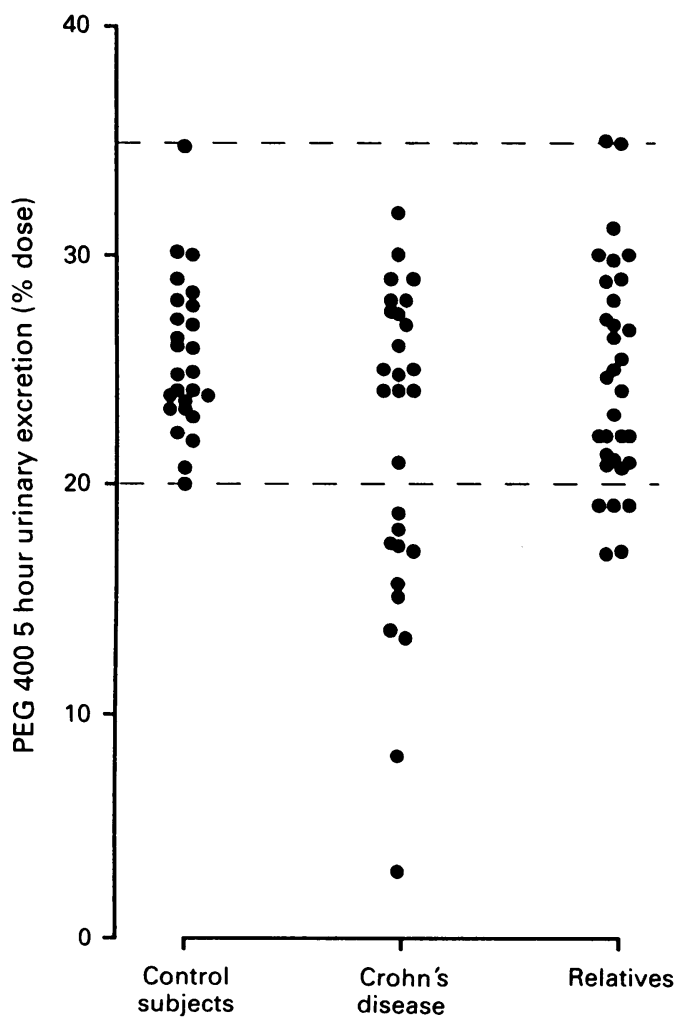

Figure 1: Five hour urine excretion (\% dose) of polyethylene glycol 400.

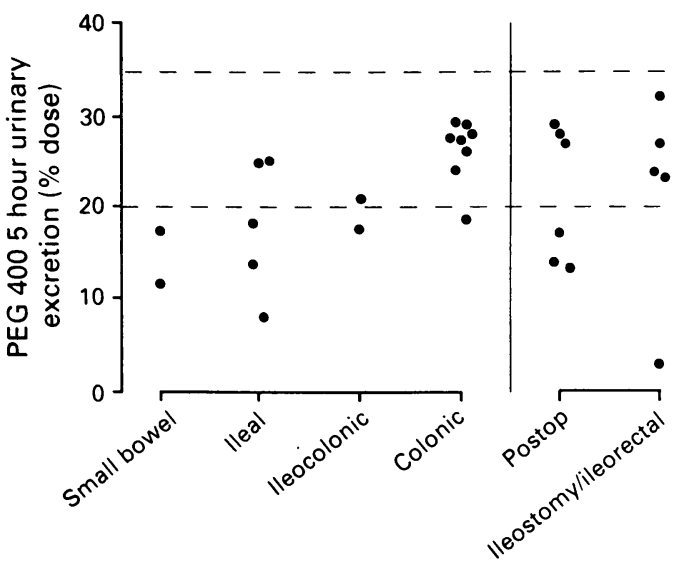

Figure 2: Polyethylene glycol 400 permeation in relation to disease location.

shown in Table II. Patients with Crohn's disease have significantly increased intestinal permeability but first degree relatives did not differ significantly from controls. Two relatives with increased intestinal permeability had a high alcohol intake.

\section{Discussion}

The intestinal barrier function is thought to be relevant to the aetiology and pathogenesis of many intestinal diseases. ${ }^{10-13}$ While the precise mechanism is uncertain it is suggested that disruption of the barrier function could allow the permeation of luminal antigens and predispose to disease by immunological mechanism. The question is, to what extent does the permeation of PEG400, L-rhamnose, lactulose and ${ }^{51}$ CrEDTA reflect disruption of the intestinal barrier to such constituents? While this has not been systematically investigated, available data suggest that the permeation of ${ }^{51} \mathrm{CrEDTA}$ correlates with plasma levels of IgA immune complexes in patients with IgA nephritis. ${ }^{17}$ Moreover in the experimental animal there is a significant correlation between ${ }^{51} \mathrm{CrEDTA}$ permeation rates on the one hand and bacterial chemotactic peptide and ovalbumin permeation, suggesting that water soluble macromolecules do share the ${ }^{51}$ CrEDTA permeation pathway. ${ }^{1819}$ Comparative studies and analysis of marker permeation in disease shows that the permeation of lactulose mirrors that of ${ }^{51} \mathrm{CrEDTA} .{ }^{15}$ L-rhamnose, however, permeates the intestinal mucosa much more efficiently and behaves much like $\mathrm{D}$-xylose in disease, implying that it uses a different permeation pathway to that of ${ }^{51} \mathrm{CrEDTA}$ and lactulose. This assumption indeed underlies the principle of differential urine excretion of orally administrated test probes as a specific measure of intestinal permeability, which has widespread acceptance in theory as well as in practice. ${ }^{12}$ The permeation of these markers in the current study conforms to that found previously in patients with Crohn's disease $^{20-23}$ and their first degree relatives. ${ }^{2425}$ Furthermore, the hyperosmolar test used in our study would 'stress' a marginally abnormal mucosa and exaggerate any borderline abnormality among the first degree relatives.

Polyethylene glycol 400 was claimed to be an 
ideal intestinal permeability probe ${ }^{26}$ but it is clear that it does not conform to the principle of differential urine excretion of orally administered test substances. The various polymers share a permeation pathway which is distinct and of much greater capacity than that used by lactulose and ${ }^{51} \mathrm{CrEDTA} .{ }^{12}{ }^{13} 15$ Although there is concern about the completeness of urine excretion of PEG400 after intravenous administration, the main difficulty has been to explain why PEG400 permeates the intestinal mucosa 50-100 times more efficiently than ${ }^{51} \mathrm{CrEDTA}$ and lactulose, despite similar molecular size and aqueous solubility. ${ }^{15}$ PEG400 differs markedly in shape from ${ }^{51} \mathrm{CrEDTA}$ and lactulose and behaves much more like L-rhamnose and mannitol in response to physiological stresses and in disease suggesting that it uses a different permeation pathway to ${ }^{51}$ CrEDTA and lactulose. ${ }^{1527}$ The precise anatomical correlation of these physiologically defined pathways are, however, unknown.

In the present study, patients with Crohn's disease involving the small intestine had significantly reduced permeation of PEG400 in agreement with two other studies. ${ }^{28}{ }^{29}$ Hollander et al, however, found the permeation of PEG400 to be significantly increased both in patients with Crohn's disease and their first degree relatives. The reasons for these discrepancies are not immediately obvious but it is clear that the possible effect of intestinal resection was not a factor in our patients. ${ }^{9}$ Hollander et al administered PEG400 with a light test meal but this is unlikely to account for the differences. The most striking difference between these two studies is the excretion of PEG400 in controls. While our controls excreted $20-37 \%$ of the orally administered test dose the corresponding range reported by Hollander $e t$ al is approximately $1 \cdot 3$ $8.0 \%$ with a mean excretion of $3 \cdot 8 \%$. These low control excretion values have not been reported by any other group. ${ }^{2628-30}$

These studies show normal intestinal permeation and permeability to test markers in first degree relatives with Crohn's disease. A genetically determined abnormality of intestinal permeability inferred by the findings of Hollander et al does not appear to be an important aetiological factor in Crohn's disease.

1 Kirsner JB, Shorter RG. Recent developments in nonspecific inflammatory bowel disease. N Engl f Med 1982; 306: 837 48

2 Shorter RG, Huizenga KA, Spencer RJ. A working hypothesis for the etiology and pathogenesis of nonspecific inflammator bowel disease. Dig Dis 1972; 17: 1024-32.

3 Teahon K, Smethurst P, Pearson M, Levi AJ, Bjarnason I. The effect of elemental diet on intestinal permeability and inflammation in Crohn's disease. Gastroenterology 1991: 101 : 84-9.

4 Purmann J. Genetic aspects of inflammatory bowel disease. In: Goebell H, Peskar BM, Malchow H, eds. Inflammatory bowel disease - Basic research and clinical implications. Falk symposium 46. Lancaster: MTP Press Ltd, 1988; 203-13.

5 Biedmond I, Weterman IT, Rood J, et al. Search for genetic markers associated with Crohn's disease in the Netherlands. In: Pena AS, Weterman IT, Booth CC, Stroben W. Recent advances in Crohn's disease. The Hague: Nijoff, 1981: $197-$ 203

6 Lewkonia RM, McConnell RB. Familial inflammatory bowe disease - heridity or environment? Gut 1976; 17: 235-43.

7 Farmer RC, Michener WM, Mortimer EA. Studies of family history among patients with inflammatory bowel disease. In Farmer RG, ed. Clinics in gastroenterology. London: WB Saunders, 1986: 271-8.

8 Hollander D, Vadheim CM, Brettholz E, Petersen GM, Delahunty T, Rotter JI. Increased intestinal permeability in patients with Crohn's disease and their relatives. Ann Intern Med 1986; 105: 883-5.

9 Hollander D. Crohn's disease - a permeability disorder of the tight junction. Gut 1988; 29: 1621-4.

10 Walker AW, Isselbacher KJ. Uptake and transport of macromolecules by the intestine. Possible role in clinical disorders. Gastroenterology 1974; 67: 531-50.

11 Powell DW. Barrier function of epithelia. Am F Physiol 1981 241: G275-88

12 Menzies IS. Transmucosal passage of inert molecules in health and disease. In: Skadhauge E, Heintze K, eds. Intestinal absorption and secretion. FALK symposium 36. Lancaster: MTP Press, $1984 ; 527-43$.

13 Bjarnason I, Peters TJ, Levi AJ. Intestinal permeability; clinical correlates. Dig Dis 1986; 4: 83-92.

14 Noone C, Menzies IS, Banatvala JE, Scopes JW. Intestinal permeability and lactose hydrolysis in human rotaviral germeability and lactose hydrolysis in human rotavira differential sugar permeation. Eur 7 Clin Invest 1986; 16: $217-25$

15 Maxton DG, Bjarnason I, Reynolds AP, Catt SD, Peters TJ Menzies IS, Lactulose, "Cr-labelled ethylenediminetetraacetate, L-rhamnose and polyethyleneglycol 400 as probe markers for assessment in vivo of human intestinal permeability. Clin Sci 1986; 71: 71-80.

16 Menzies IS, Mount JN, Wheeler MJ. Quantitative estimation of clinically important monosaccharides in plasma by rapid thin-layer chromatography. Ann Clin Biochem 1978; 15: 6576.

17 Davin JC, Forget $P$, Mahieu PR. Increased intestinal permeability to $\left({ }^{5} \mathrm{Cr}\right) \mathrm{EDTA}$ is correlated with IgA immune complex-plasma levels in children with IgA-associated nephropathies. Acta Paediatr Scand 1988; 77: 118-24.

18 Ramage JK, Stanisz A, Scicchitano R, Hunt RH, Perdue MN Effects of immunological reactions on RAS intestinal epithelium. Correlation of increased intestinal permeability to chromium-51 labelled ethylenediaminetetraacetatic acid to chromium-51 labelled ethylenediaminetetraacetatic acid and ovalbumen during acute inflam

19 Ferry DM, Butt TJ, Broom MR, Hunter J, Chadwick VS Bacterial chemotactic oligopeptides and the intestinal mucosal barrier. Gastroenterology 1989; 97: 61-7.

20 Pearson ADJ, Eastham EJ, Laker MF, Craft AW, Nelson R Intestinal permeability in children with Crohn's disease and coeliac disease. BMF 1982; 285: 20-1.

21 Bjarnason I, O'Morain C, Levi AJ, Peters TJ. Absorption of 51-Chromium labelled ethylenediaminetetraacetate in inflammatory bowel disease. Gastroenterology 1983; 85: 31822 .

22 Ukabam SO, Clamp JR, Cooper BT. Abnormal intestinal permeability to sugars in patients with Crohn's disease of the permeability to sugars in patients with Crohn's diseas

23 Sanderson IR, Boulton P, Menzies IS, Walker-Smith JA. Improvement of abnormal lactulose/L-rhamnose permeability in active Crohn's disease of the small bowel by an elemental diet. Gut 1987; 28: 1073-6.

24 Ainsworth M, Eriksen J, Rasmussen JW, Schaffalitzkydemuckadel OB. Intestinal permeability of "Cr-labelled ethylenediaminetetraacetic acid in patients with Crohn's disease and their healthy relatives. Scand $\mathcal{f}$ Gastroenterol 1985; 24: 993-8.

25 Katz KD, Hollander D, Vadheim CM, McElree C, Delahunty T, Dadufalza VD, et al. Intestinal permeability in patients with Crohn's disease and their healthy relatives. Gastroenterology 1985; 97: 927-31.

26 Chadwick VS, Phillips SE, Hofmann AF. Measurements of intestinal permeability using low molecular weight polyethylene glycols (PEG400) II. Application to normal and abnormal permeability states in man and animals. Gastroenterology 1977; 73: 247-51.

27 Hollander D, Ricketts D, Boyd CAR. Importance of probe molecular geometry in determining intestinal permeability. Can f Gastroenterol 1988; 2: 35-8A

28 Magnusson K-E, Sundqvist T, Sjödahl R, Tageson C. Altered intestinal permeability to low molecular weigh polyethyleneglycols (PEG400) in patients with Crohn's disease. Acta Chir Scand 1983; 149: 323-7.

29 Jenkins RT, Goodacre RL, Rooney PJ, Bienenstock J Sivakemaran T, Walker WHC. Studies of intestinal permeability in inflammatory diseases using polyethylene glycol 400. Clin Biochem 1986; 19: 298-302.

30 Olaison G, Sjodahl R, Tageson C. Abnormal intestinal permeability in Crohn's disease. A possible pathogenic factor. Scand F Gastroenterol 1990; 25: 321-78. 